\title{
As práticas de in/exclusão na escola e a redefinição do conhecimento escolar: implicações contemporâneas
}

\section{Practices of in/exclusion at school and the school knowledge redefinition: contemporary implications}

\author{
Kamila Lockmann ${ }^{1}$
}

\begin{abstract}
RESUMO
O texto tem como objetivo analisar as estratégias pedagógicas desenvolvidas para atender alunos anormais incluídos em escolas regulares. Para isso, analisaram-se discursos materializados em fichas de encaminhamentos e coletados em entrevistas semiestruturadas realizadas com professores e diretores de uma Rede Municipal da Região Metropolitana de Porto Alegre. Tomando como suporte teórico-metodológico o pensamento foucaultiano foi possível perceber que a inclusão escolar, quando aparece como um imperativo do nosso tempo, faz com que as formas de ser, de agir e de se comportar na escola assumam uma centralidade ímpar nos currículos a ponto de produzirem uma redefinição dos conhecimentos escolares. Aquilo que entendíamos como conhecimento escolar acaba incluindo outras dimensões, predominantemente, pautadas pelo prisma psicológico. Esse deslocamento das práticas pedagógicas pode ser visualizado pela proliferação dos atendimentos oferecidos aos alunos: psicopedagogia, psicologia, psicomotricidade, equoterapia, entre outros. As descrições sobre os alunos produzidas pelos professores não enfatizam aprendizagens vinculadas a determinadas áreas de conhecimento ou às disciplinas escolares, mas destacam, sobretudo, as formas como cada sujeito precisa aprender a operar sobre si mesmo, conduzindo suas próprias condutas num claro e evidente predomínio das técnicas de si. Sendo assim, neste artigo argumento que essas práticas pedagógicas, ao centrarem seu olhar nas formas de condução
\end{abstract}

DOI: $10.1590 / 0104-4060.34677$

1 Universidade Federal do Rio Grande, Instituto de Educação. Rio Grande, Rio Grande do Sul, Brasil. Avenida Itália, Km 8. Carreiros. CEP: 96203-900. 
de si mesmo, acabam redefinindo os conhecimentos escolares e ligando-os inexoravelmente com conteúdos psicológicos, os quais passam a assumir a centralidade dos processos educativos.

Palavras-chave: inclusão; práticas pedagógicas; conhecimento escolar.

\begin{abstract}
The text aims to analyze the pedagogical strategies designed to meet disabled pupils who study in mainstream schools. For this, we analyzed discourses materialized in cards of referrals which were collected in semistructured interviews with teachers and principals of a Municipal Net from the Metropolitan Region of Porto Alegre city. The theoretical and methodological support was Foucault's thought, and with that support it was possible to see that school inclusion, when it appears as an imperative of our time, makes the forms of being, acting and behaving at school take a unique centrality in the curriculum to the point of producing a redefinition of school knowledge. What we understood just as school knowledge includes now other dimensions that are predominantly guided by a psychological prism. This shift of pedagogical practices can be viewed by the proliferation of care offered to students: educational psychopedagogy, psychology, psychomotricity, hippotherapy, among others. The students' descriptions produced by teachers do not emphasize learning linked to certain areas of knowledge or to the school subjects, but they highlight especially the ways each subject must learn to operate on himself, leading his own practices in a clear and evident predominance of self techniques. Therefore, in this article I argue that these pedagogical practices, in order to focus their gaze on ways of self conduction, end up redefining the students' knowledge and linking them inexorably with psychological contents, which shall assume the centrality of educational processes.
\end{abstract}

Keywords: inclusion; pedagogical practices; school knowledge.

\title{
Das discussões iniciais
}

A inclusão escolar tem se constituído como um imperativo dos tempos contemporâneos e tem definido novas formas de trabalhar "pedagogicamente" com os alunos "incluídos" na escola. Digo que a inclusão se tornou um imperativo atual visto que ela não se apresenta como algo passível de questionamentos, de suspeitas ou de problematizações. Tem se tornado uma verdade inquestionável que vem moldando nossas formas de ser e agir com os alunos nas salas de 
aula brasileiras. Neste contexto, quando olhamos para as práticas de inclusão desenvolvidas na atualidade e lançamos problematizações sobre a forma como elas vêm acontecendo e os efeitos que vêm produzindo no trabalho da escola, muitas vezes somos posicionados como pesquisadores que se colocam contra a proposta inclusiva. Não se trata disso! Ao iniciar um texto que pretende olhar para os efeitos que a inclusão vem produzindo no interior das práticas pedagógicas contemporâneas e mais propriamente no campo da avaliação, não pretendo assumir uma postura valorativa no sentido de ser contra ou a favor da inclusão. Essa alternativa me parece simplista e restrita demais. Como pesquisadora do campo da inclusão escolar, assumo uma postura analítica, a qual me parece muito mais produtiva e me permite analisar quais as práticas pedagógicas vêm sendo desenvolvidas para atender aos ditos alunos de inclusão e que efeitos essas práticas têm produzido na escola.

Dessa forma, o presente texto tem como objetivo analisar as estratégias pedagógicas desenvolvidas para atender alunos anormais ${ }^{2}$ incluídos em escolas regulares, assim como algumas descrições avaliativas produzidas sobre esses mesmos alunos. Para isso, analisei discursos materializados em fichas de encaminhamentos preenchidas por professores e coordenadores pedagógicos quando desejam encaminhar alunos a setores especializados. Além disso, também foram realizadas entrevistas semiestruturadas com professores e diretores de uma Rede Municipal da Região Metropolitana de Porto Alegre. Diante dos achados da pesquisa e tomando como suporte teórico-metodológico o pensamento foucaultiano, foi possível perceber que a inclusão escolar, quando aparece como um imperativo do nosso tempo, faz com que as formas de ser, de agir e de se comportar na escola assumam uma centralidade ímpar nos currículos a ponto de produzirem uma redefinição dos conhecimentos escolares, a qual ocorre de forma imanente com um deslocamento no próprio campo da avaliação. Aprender a controlar os impulsos, gerenciar conflitos emocionais, agir adequadamente no espaço escolar e respeitar regras coletivas para um bom convívio social parecem ser as aprendizagens destacadas como importantes e necessárias para a escola contemporânea, sobretudo, quando se fala em inclusão escolar.

Partindo de tal entendimento, o presente texto foi organizado da seguinte forma: Primeiramente, abordo de forma bastante breve alguns aspectos da metodologia da pesquisa, assim como o entendimento de discurso que acompanha

2 Apoiada no pensamento de Michel Foucault, opto por utilizar o termo anormais por entender que, independentemente da nomenclatura utilizada para referir esses sujeitos, está-se marcando suas diferenças e posicionando-os como normais e anormais através de uma processo constante de comparabilidade. Mesmo aquelas terminologias consideradas politicamente corretas, como é o caso de "pessoas com necessidades educacionais especiais", também fazem essa operação de classificação. 
o trabalho. Na seção posterior, apresento as análises desenvolvidas na pesquisa mostrando, num primeiro momento, que as descrições produzidas pelos professores sobre os alunos não enfatizam aprendizagens vinculadas a determinadas áreas de conhecimento ou às disciplinas escolares, mas destacam, sobretudo, as formas de ser, de agir e de se comportar na escola apresentadas pelos alunos ditos "incluídos". Ao preencher as fichas de encaminhamento analisadas nesta investigação, os professores estão produzindo avaliações sobre os alunos, descrevendo o que eles são, ou como deveriam ser, apontando aspectos a serem melhorados para que se tenha sucesso na escola. Tais descrições centram-se nas formas de condução que o sujeito deveria desenvolver sobre si mesmo, conduzindo suas próprias condutas num claro e evidente predomínio das técnicas de si. Num segundo momento das análises, destaco as estratégias desenvolvidas pela escola para atender esses alunos a partir das quais foi possível perceber um movimento de pulverização das práticas de encaminhamento desses alunos para diferentes setores, tais como: psicopedagogia, psicologia, psicomotricidade, arteterapia, dançaterapia, equoterapia, entre outros. Trata-se de uma espécie de proliferação discursiva sobre as formas de atendimento oferecidas aos alunos anormais e um certo silenciamento das práticas de ensino.

Depois de mostrar esses deslocamentos, na última seção, mostro como isso tem produzido uma redefinição dos conhecimentos escolares na atualidade. Aquilo que entendíamos como conhecimento escolar acaba incluindo outras dimensões, predominantemente, pautadas pelo prisma psicológico, pelas formas de ser, de se conduzir e de se relacionar com os demais. Eis, portanto, a Tese que sustento neste artigo: a de que as práticas pedagógicas contemporâneas, ao centrarem seu olhar nas formas de condução de si mesmo, acabam redefinindo os conhecimentos escolares e ligando-os inexoravelmente com conteúdos psicológicos, os quais passam a assumir a centralidade dos processos de avaliação na atualidade.

\section{Entre o discurso da inclusão e o discurso da avaliação: possibilidades teórico-metodológicas de pesquisa}

[...] em toda sociedade a produção do discurso é ao mesmo tempo controlada, selecionada, organizada e redistribuída por certo número de procedimentos que têm por função conjurar seus poderes e perigos, dominar seu acontecimento aleatório, esquivar sua pesada e temível materialidade (FOUCAULT, 2004, p. 8-9). 
Este estudo se orienta pela hipótese de que há uma ordem discursiva mais ampla que delimita os discursos escolares considerados válidos numa determinada época, estabelecendo, por meio de uma variedade de regras, o que se pode dizer sobre o aluno, sobre suas aprendizagens, sobre as metodologias de ensino, sobre a inclusão escolar ou sobre a avaliação. Dessa forma, os discursos analisados nesta pesquisa são compreendidos como fazendo parte de um contexto discursivo maior, que controla a produção do discurso. Esse controle do discurso permite que alguns ditos possam ser pronunciados em determinados espaços sociais e por determinadas pessoas ou que, no lugar disso, sofram uma interdição discursiva, sendo, dessa forma, anulados, rejeitados ou silenciados. Isso significa que existe um controle ou uma determinada ordem sobre a produção do discurso. No que se refere ao campo da inclusão escolar e da avaliação, isso não é diferente. Acostumamo-nos a escutar seguidamente que a inclusão promove o respeito à diversidade, desenvolve a tolerância, contribui para a formação de sujeitos mais humanos e solidários. Também parecem ser cada vez mais presentes os discursos que enfatizam o respeito ao ritmo individual de cada aluno, a avaliação como processo contínuo, permanente e flexível. Tais discursos estão presentes em documentos oficiais do Ministério da Educação, na mídia de uma forma geral, em revistas e artigos científicos e, obviamente, no interior das escolas contemporâneas.

Assim, podemos compreender que os discursos que hoje circulam no campo da educação não são escolhas individuais autônomas, mas escolhas governadas por um conjunto de valores que nos cercam e direcionam nosso olhar para que façamos determinadas ações em nosso cotidiano de trabalho. Tais discursos não partem, então, de uma origem primeira no sujeito falante, mas são antes discursos que se corporificam numa determinada época. A partir desse entendimento, não se pode destacar os professores como origem primeira de um discurso sobre a inclusão escolar. Isso aponta para uma ressalva que é preciso considerar. Ao problematizar alguns dos discursos encontrados nesta investigação, não estou apontando culpados nesse processo de produção e circulação discursiva. Antes disso, ou no lugar disso, trabalho com o entendimento de que o discurso dos professores produz e ao mesmo tempo é produzido por uma determinada forma de ser do pensamento pedagógico contemporâneo e da racionalidade política em que estamos imersos. Meu interesse pelos discursos dos professores não está relacionado a uma suposta identidade autônoma, que produz um discurso escolar livre de regras, de interdições, de proibições ou exaltações. Meu interesse não aponta para um sujeito falante, supostamente autor do seu discurso. Foucault (2001a) já questionava: "que importa quem fala?" Os discursos que circulam acerca da inclusão escolar e da avaliação se 
atrelam a uma trama discursiva muito maior do que o próprio autor. Por isso, muito mais importante que saber quem é o autor, o que importa aqui são os ditos, o próprio discurso. Aqui, “o autor, não [é] entendido, é claro, como o indivíduo falante que pronunciou ou escreveu um texto, mas o autor como o princípio de agrupamento do discurso, como unidade e origem de suas significações, como foco de sua coerência" (FOUCAULT, 2004, p. 26). Mais do que saber quem o pronuncia ou buscar os seus significados intrínsecos, me interessa analisar os discursos escolares como pertencentes a uma ordem discursiva que os controla, os regula e os posiciona como verdadeiros ou falsos. Assim, o foco dessa investigação não será analisar especificamente o discurso de um determinado professor ou interpretar o significado de suas palavras, mas perceber como esse discurso se encontra inserido em uma racionalidade específica de nossos tempos que estabelece o que pode ser dito, o que tem validade ou o que, no lugar disso, precisa ser anulado, interditado ou excluído.

A partir desse entendimento olho para os materiais desta investigação que se constituem em fichas de encaminhamentos preenchidas por professores e coordenadores pedagógicos das escolas e por entrevistas semiestruturadas realizadas com alguns professores e diretores de uma rede pública de ensino. Ao olhar para esses materiais tinha como objetivo coletar informações sobre as alternativas pedagógicas que os professores utilizam para trabalhar com os alunos incluídos na sala de aula, como organizam suas aulas, que estratégias empregam para explicar determinados conteúdos, que visões de metodologia, planejamento, currículo e avaliação se fazem presentes no seu trabalho pedagógico. A partir das análises pude compreender que os discursos materializados nas fichas de encaminhamento ou coletados neste ritual nada neutro em que se constitui a prática da entrevista, apresentam uma centralidade no aluno e nos seus processos de aprendizagem e uma certa interdição do ensino e da dimensão pedagógica do papel do professor. Além disso, quando falam das aprendizagens dos alunos, destacam, sobretudo, formas de ser e de se comportar na escola como justificativas para o encaminhamento dos alunos a uma variedade de especialistas. Junto com isso, os procedimentos pedagógicos e as intervenções realizadas pela escola deslocam-se para outros campos epistemológicos, convocando psicólogos, médicos e psicopedagogos para realizarem o atendimento desses alunos. A escola, o professor e o trabalho pedagógico parecem ocupar um lugar secundarizado nos processos de inclusão e de avaliação desses sujeitos escolares. Esses e outros aspectos serão abordados nas seções seguintes deste artigo. 


\section{Sobre os achados da pesquisa: a centralidade na condição das condutas dos sujeitos escolares}

Ao analisar os dados coletados na pesquisa, percebe-se uma centralidade atribuída às formas de condução dos sujeitos escolares. Isso ocorre, pode-se dizer, em diferentes instâncias. Primeiramente pode-se notar que ao preencher as fichas de encaminhamento dos alunos, os professores e coordenadores pedagógicos justificam a necessidade desse atendimento por meio de aspectos morais e comportamentais. Tais discursos relacionam-se aos comportamentos dos alunos, às suas formas de agir, à sua agressividade ou à sua passividade, aos seus valores e interesses, enfim, às condutas que os alunos apresentam e às formas que encontram de interagirem com os demais. Trata-se daquilo que chamei, para essa investigação, de moralização dos infantis.

O termo moralização foi tomado emprestado de Foucault (2001b), quando se refere a uma série de faltas, de comportamentos inadequados ou de atitudes indesejadas cometidas por um sujeito em sua infância e que, naquele momento, serviam de argumentação para o perito psiquiatra no decorrer do julgamento de um crime. Ele alega que essa série de faltas pode ser chamada de parapatologia, ou seja,

[...] próxima da doença, mas uma doença que não é uma doença, já que é um defeito moral. [...] essa série é a prova de um comportamento, de uma atitude, de um caráter, que são moralmente defeitos, sem ser nem patologicamente doenças, nem legalmente infrações (FOUCAULT, 2001b, p. 25).

No curso de 1975, Os Anormais, Foucault cita alguns laudos produzidos por peritos psiquiatras que descreviam cenas da infância do réu. Suas atitudes, o seu relacionamento com os pais, com colegas e com pessoas próximas, a forma agressiva como se comportava já desde muito cedo eram relatos que marcavam o seu desvio moral. Por isso, esses fatos eram trazidos à tona pelo perito psiquiatra, a fim de justificar um crime cometido. É interessante observar o que o perito dizia sobre o réu: "[...] ele brincava com armas de madeira, [...] ele magoava os pais, ele matava aula, ele não aprendia a lição" (FOUCAULT, 2001b, p. 46).

Semelhantes práticas de descrição das atitudes e dos comportamentos das crianças e jovens são recorrentes também na atualidade, porém com outros 
significados. Não se pode afirmar que são as mesmas práticas, pois elas se modificam, se atualizam e operam de formas diferenciadas nos dias de hoje. Se, naquele momento, o objetivo era incriminar o réu pela descrição de suas atitudes infantis, agora se pode dizer que tais descrições funcionam a partir de outra lógica, de outra forma de ser do pensamento político que aposta na prevenção no lugar da penalização. Portanto, o que ocorre é a reativação de algumas práticas, porém com objetivos distintos.

A partir da análise das fichas de encaminhamento, pude evidenciar a existência de três grupos de sujeitos que são apontados pelas descrições docentes como tendo problemas de conduta e que necessitam de atendimentos especializados. O primeiro deles, os "potencialmente criminosos"; são aqueles sujeitos que se mostram agressivos em suas relações e apresentam uma série de desvios de conduta, que podem constituir-se em um perigo constante para si mesmos e àqueles com os quais convivem; o segundo grupo de alunos são aqueles a quem denominei "instauradores do caos", ou seja, alunos que apresentam atitudes indesejadas, condutas inadequadas ou comportamentos inusitados. São aqueles alunos descritos como agitados, inquietos, mal-educados, sem limites, enfim, os "famosos" indisciplinados. Necessariamente, não se constituem em uma ameaça para os demais, porém, em virtude da sua agitação constante, atrapalham o andamento das aulas e prejudicam o rendimento da sua aprendizagem, assim como o de seus colegas. O terceiro grupo, "os sujeitos (in)cômodos", são alunos que aparentemente não se constituiriam como preocupações para os professores, pois não são agressivos, não perturbam as aulas e também não são uma ameaça para os outros. Porém, devido à postura retraída e distante que demonstram, assumem um lugar de improdutividade na escola e, por isso, apesar de seu comodismo, causam incômodo, preocupando os professores e a escola como um todo. São, portanto, os quietos, os lentos, os distraídos, os tímidos demais. É possível dizer que todos eles, sejam agressivos, agitados ou quietos demais, escapam da normalidade e, por isso, são alvo das preocupações de professores e especialistas, que desenvolvem intervenções educacionais e terapêuticas, a fim de moralizar, de acordo com alguns princípios, suas formas de ser, agir e viver no mundo. Vejamos, por meio dos excertos das fichas analisadas, alguns discursos que descrevem e, ao mesmo tempo, prescrevem cada um dos sujeitos desses três grupos:

\section{a) Os potencialmente criminosos:}

Apresenta muita dificuldade de relacionamento com os colegas, falsifica bilhetes, conta histórias inventadas por ela e acredita nelas. (6C, 2007). 
Ele resiste em atender qualquer combinação [...]. Resolve a maioria das situações com agressividade. Algumas vezes pega coisas dos outros sem pedir. A criança foge de casa e fica até às $22 \mathrm{~h}$ na rua, é agressivo e diz que quer ser ladrão. (1L, 2008).

Bate nos irmãos menores, utiliza facas e objetos variados para manifestar sua inconformidade com algumas situações. (9A, 2007).

\section{b) Os instauradores do caos:}

Está apresentando resistência em respeitar professores e colegas, perturbando as propostas em sala de aula. Tem dificuldade em permanecer sentado em seu lugar no decorrer das explicações e da realização das tarefas. Distração com muitas conversas e comentários que não são referentes à aula. Brincadeiras em sala de aula. Fica na janela chamando os alunos que estão no pátio. Anda pela sala, vai à porta muitas vezes e não aceita quando os professores chamam sua atenção. Responde dizendo que ninguém manda nele e que ele faz o que ele quer. Quando repreendido pela professora, manda esta calar a boca e diz que ela não manda nele. (1D, 2007).

O aluno vem apresentando dificuldade em aceitar as regras e combinações feitas na sala de aula e em casa. Quando fica agressivo, tapa os ouvidos e costuma jogar o que tem na mão longe. L. apresenta muita dificuldade com o limite. (2J, 2008).

Ele grita na sala de aula, ele canta, ele levanta, ele reclama. Ele tem que ficar relatando coisas assim, fala sozinho, chama os colegas, dai, de repente, já está cantando uma música e diz: eu não vou mais fazer isso, que horas que eu tenho que ir pra casa, que horas que minha mãe vem ou que horas é a merenda? (Entrevista, 3A).

\section{c) Os sujeitos (in)cômodos:}

Nas poucas aulas que J. compareceu, ficou muito reservado, procurava sentar com o colega D. e quase não falava com os colegas. Faz as atividades, mas não demonstra alegria, desejo, interesse. J. mostrase muito apático e por seu modo de ser é chamado pelos colegas de "mudinho." (1H, 2008). 
Demora excessivamente cansando com frequência e por isso fica um longo tempo olhando para o quadro, ou se dispersa olhando para outros lugares da sala. Preciso incentivá-lo várias vezes para que termine sua cópia. $(5 F, 2007)$.

Sua maior dificuldade consiste no fato de demorar-se para concluir ou até mesmo executar suas tarefas, não por conversas com os colegas ou sair do lugar, mas sim por não conseguir concentrar-se. Tem bom relacionamento com os colegas e a professora. Não fala no grande grupo e quando quer falar com a professora ofaz com voz praticamente inaudivel. (10D, 2007).

Essas atitudes geram grande preocupação no espaço escolar, pois sinalizam um desvio moral, marcam uma forma de ser e de agir desses sujeitos que pode se constituir num risco, tanto para si, quanto para os demais. O primeiro grupo torna-se um perigo para os colegas de classe e para os próprios professores, em vista das atitudes agressivas que manifestam e dos valores distorcidos que evidenciam. Futuramente, também poderão se constituir um perigo para a própria sociedade, por meio de infrações e transgressões que possam continuar cometendo, talvez em maior grau. Esses sujeitos produzem aquilo que se pode chamar de pânico moral, ou seja, aqueles

[...] fenômenos que surgem como evidência de uma preocupação social profunda sobre temas como moralidade sexual, consumo de drogas, ou outras formas de comportamentos considerados ameaçadores para a sociedade em um determinado momento (MISKOLCI, 2006, p. 231).

No que se refere ao segundo grupo, pode-se dizer que tais alunos instauram o caos e a desordem por onde passam, com atitudes que chocam, que desestabilizam, que perturbam o andamento das atividades escolares, pensadas e planejadas no interior de uma ordem moral e pedagógica. Esses sujeitos passam a ser o centro de uma das maiores preocupações da escola atual, a saber, a indisciplina escolar. Para a instituição escolar, a indisciplina interfere diretamente no andamento das aulas e prejudica o desempenho escolar tanto dos alunos indisciplinados quanto de seus colegas de classe. Parece que tais alunos não vão conseguir aprender, pois não se dedicam às atividades, não prestam atenção às aulas, não realizam as atividades propostas e, ao mesmo tempo, não permitem que os outros aprendam. Prejudicam a si próprios e aos demais. 
Práticas escolares voltadas ao disciplinamento dos sujeitos com o intuito de ajustar suas condutas de acordo com princípios morais, considerados adequados para a vida em sociedade, já estavam presentes tanto no pensamento comeniano em fins do século XVI, quanto no pensamento kantiano, desenvolvido no século XVIII. Ambos os pensadores salientavam a importância de as crianças frequentarem a escola para que a disciplina atue sobre seus corpos, sobre suas almas, sobre sua moralidade. A ênfase da educação proposta por Kant e Comenius encontra-se no "ser" e não no "saber". Comenius (2002, p. 100) já apontava como "[...] infeliz a instrução que não se converte em moralidade e piedade." $\mathrm{Na}$ obra de Kant, podem-se encontrar suas conhecidas palavras, quando afirma que

[...] as crianças são mandadas cedo à escola, não para que aí aprendam alguma coisa, mas para que aí se acostumem a ficar sentadas tranquilamente e a obedecer pontualmente àquilo que lhes é mandado, a fim de que no futuro elas não sigam de fato e imediatamente cada um de seus caprichos (KANT, 1996, p. 12).

Atualmente, essas práticas de disciplinamento continuam presentes dentro da escola, porém, se articulam, se entrelaçam ou se imbricam com outras tantas formas de intervir sobre a conduta dos sujeitos ou de fazê-los intervir sobre si mesmos. Por mais que a disciplina continue presente nas práticas escolares nos dias de hoje, parece haver um predomínio das técnicas de si ou das formas de governamento ético, em que o próprio sujeito age sobre si mesmo. Veremos isso mais adiante, quando lançarmos um olhar sobre as estratégias desenvolvidas pela escola para intervir sobre esses sujeitos. Até aqui, estamos olhando apenas para as descrições/prescrições produzidas pelos docentes para justificar ou respaldar a necessidade de um atendimento especializado. $O$ terceiro grupo que necessita desse tipo de intervenção talvez seja justamente o que potencializa o uso dessas técnicas de si na escola, pois para eles não se deseja o disciplinamento ou a contenção de suas atitudes, pelo contrário, deseja-se que esse sujeito se expresse, se comunique, se relacione, se posicione diante dos acontecimentos escolares. Sua apatia, desatenção, distração e lentidão se constituem em preocupações para a escola e para os professores. Mas se os sujeitos descritos não incomodam, não desestabilizam e não prejudicam a ordem escolar, por que se tornam, também, uma preocupação? No estudo realizado por Caliman (2006), sobre a constituição do sujeito desatento, ela afirma que a desatenção está relacionada com o fracasso, pois o sujeito desatento é “[...] incapaz de gerenciar sua própria atenção e ação, incapaz de direcionar sua energia mental para os fins corretos e 
mais importantes, incapaz de realizar os planos futuros que ele mesmo propôs." (CALIMAN, 2006, p. 54). Portanto, "“...] o desatento se identifica com o sujeito não produtivo, incapaz de autogestão.” (CALIMAN, 2006, p. 68).

Desse modo, pode-se inferir que a escola volta sua atenção e suas intervenções para todos aqueles sujeitos que não se encaixam nos padrões estabelecidos, apresentando desvios que se pode denominar, nesse caso, desvios morais. Fica evidenciado que a preocupação da escola não se direciona tanto para os conhecimentos que estão sendo adquiridos ou não pelos alunos, mas age sobre os corpos e almas que não obedecem a um padrão moral estabelecido como necessário para a vida social e coletiva. O historiador Jorge Ramos do Ó já atentava para esse fato, destacando que

Para qualquer alma em crise, debatendo-se entre as aspirações românticas de sua idade e as realidades brutais da vida, o ministrar-se apenas uma lição de latim, de matemática, de geografia ou geologia, era bem pouco. [...] A instrução que fornecia elementos de aplicação prática era de um grande valor, mas a educação, isto é, a modelação do caráter, a formação superior das almas era de um valor muito maior (Ó, 2003, p. 446).

É justamente essa ênfase na moralidade que encontramos na escola, não só quando ela descreve suas preocupações diante de determinados sujeitos escolares, justificando assim a necessidade de um atendimento especializado, mas também quando ela aponta as estratégias "pedagógicas" que realiza para atender esses sujeitos no seu cotidiano. Tanto no decorrer da análise das fichas de encaminhamento, quando se descreve o que a escola tem feito para atender tais sujeitos, quanto nos discursos coletados pelas entrevistas realizadas com os professores percebe-se a referência ao grande número de encaminhamentos de alunos a serviços de apoio pedagógico, a psicopedagogas, a psicomotricistas, a neurologistas, fonoaudiólogos etc. No decorrer da análise, o que consegui perceber não foram práticas desenvolvidas pela escola, ou pelos professores, no que se refere às suas intervenções e práticas de ensino. No lugar disso, o que encontrei foram descrições sobre os encaminhamentos que a escola realizou para cada aluno, a um conjunto de outros profissionais especializados em áreas diversas. Há, portanto, um certo silenciamento das práticas de ensino e uma pulverização das práticas de encaminhamento, uma espécie de proliferação discursiva sobre as formas de atendimento oferecidas aos alunos: 
A escola, desde o ingresso do aluno, teve papel importante auxiliando a mãe a levá-lo a especialistas e a mantê-lo nesses atendimentos (4F, 2008).

São realizados todos os procedimentos possíveis em relação ao aluno: encaminhamentos aos atendimentos especializados, participação do aluno em projetos oferecidos pela escola, acompanhamento de AFA (Projeto Aprender Fazendo), diálogo sistemático com os profissionais que atendem ao aluno. (8H, 2008).

Nas quartas-feiras ele não vem na escola porque quarta-feira é o dia que ele tem todos os atendimentos fora, tem fono, tem psicólogo e um trabalho de motricidade. (Entrevista, 2B).

As estratégias desenvolvidas pela escola afastam-se de certa maneira de intervenções pedagógicas e enfatizam uma variedade de outras técnicas e procedimentos diversos, vinculados a outros campos de saber. Todas estas estratégias, porém, aparecem como formas de governamento dos sujeitos, pois pretendem moldar suas condutas a partir de princípios considerados adequados para o convívio social. Com isso, percebe-se a ênfase que os procedimentos de condução das condutas dos sujeitos assumem no interior da escola contemporânea. Mas, como podemos falar em uma centralidade na condução das condutas nas práticas escolares atuais, se, no decorrer de a toda história da Educação, a escola sempre foi esse mecanismo de governamento e controle dos viventes? A própria Pedagogia sempre esteve atrelada às práticas de condução, como evidenciam Marín-Diaz e Noguera-Ramírez (2009, p. 130). Esses pesquisadores defendem que:

O termo pedagogia é usado desde o princípio para referir a prática de conduzir e orientar a conduta dos outros. Esta palavra, que provém do grego paidagogia, $[. .$.$] foi usada na Antiguidade para assinalar a atividade$ que realizava um escravo que conduzia, vestia, acompanhava as crianças e jovens [...] e que, ao longo de suas caminhadas, era responsável por moldar o comportamento e o caráter do jovem.

Sob esse prisma, não podemos dizer que é agora, na atualidade, que as práticas educativas apresentam uma ênfase na condução das condutas dos sujeitos, pois essa tarefa sempre foi atribuída à escola. Talvez, o que possamos dizer é que, na atualidade, as formas de governamento dos sujeitos se modificam e apresentam ênfases diferenciadas: não acontecem tanto por meio da disciplina- 
rização dos corpos e dos saberes, mas por meio de práticas de subjetivação e de governo de si. Há uma excessiva centralidade no indivíduo. Isso não significa que a disciplina deixa de existir, mas que a ênfase recai não tanto sobre um governo que age de uns sobre os outros, mas sobre um governo no qual cada sujeito age sobre si mesmo a partir das aprendizagens que desenvolve. Além disso, outro ponto importante refere-se ao próprio conceito de aprendizagem. Muitos autores têm afirmado que estamos vivendo numa sociedade da aprendizagem. Porém, como podemos falar em uma sociedade da aprendizagem se ao analisar as descrições avaliativas realizadas pelos professores sobre os avanços e retrocessos dos alunos percebemos uma ênfase nas formas de ser, de se conduzir e de se comportar em detrimento dos conhecimentos escolares. Vejamos como isso se apresenta no discurso dos professores:

Eu acho que ele cresceu muito na maturidade, no relacionamento com os colegas, ele tá entendendo melhor as coisas, o limite, ele está entendendo bem melhor. (Entrevista, 2B)

Ele aprendeu, está aprendendo a respeitar os limites e os colegas. Está mais calmo, consegue seguir as ordens dadas na escola. Acho que para essa melhora dele, os atendimentos que ele frequenta e a convivência com os outros na escola regular foi essencial. (Entrevista, 5A)

No começo do ano foi muito difícil. A gente quase desanimava [...] Ele queria pegar pedra e atirar na gente. Era bem complicado! [...] Mas agora ele já está melhor, na segunda-feira ele já sabe direitinho que tem futebol, informática. Ele já não faz mais aquele tumulto. Ele não conseguia entender a rotina, que hoje não é o dia de Educação Física, agora ele já entende. Hoje ele mesmo já vem e diz: "Hoje não tem Educação Física”. Não... hoje não, só amanhã. (Entrevista, 2B).

Ao avaliar os progressos apresentados pelos alunos, os professores destacam questões referentes à convivência na escola, à socialização, à contenção de suas emoções e ao equilíbrio emocional dos sujeitos escolares. Fica evidenciado que a escola não centra suas ações na produção de conhecimentos escolares, mas as amplia para uma variedade de âmbitos da vida humana e incide sobre a existência mesmo de cada sujeito em particular. Com isso, chama-se a atenção para a entrada, nos currículos escolares de dimensões, podemos dizer, éticas, que envolvem as relações, os sentimentos, as emoções, os conflitos internos, entre outras. Tudo isso nos mostra que há uma ampliação na própria noção de aprendizagem na atualidade, a qual passa a incluir, além de conhecimentos 
disciplinares, outras dimensões bem mais amplas da vida humana. Segundo Nóvoa (2009, p. 61),

Hoje os novos conceitos de aprendizagem envolvem, para além dos conhecimentos, as emoções, os sentimentos e a consciência, implicam o método, o estudo e a organização do trabalho, incluem a criatividade, a capacidade de resolver problemas, a inteligência e a intuição.

Veiga-Neto (2008, p. 141) postula que "[...] estamos hoje vivendo as maiores e mais radicais mudanças nos quatro elementos constitutivos desse artefato escolar: o planejamento dos objetivos, a seleção de conteúdos, a colocação de tais conteúdos em ação na escola e a avaliação". Entre esses elementos do currículo, foco minhas análises naqueles que se referem aos conteúdos ou naquilo que podemos denominar conhecimentos escolares. Argumento que, a partir das práticas que desenvolvemos no interior das escolas atualmente e, dos aspectos destacados como progressos no desenvolvimento dos alunos, podemos perceber uma redefinição contemporânea dos conhecimentos escolares e, por consequência, uma ampliação do próprio conceito de aprendizagem.

\section{Redefinições do conhecimento escolar e a ampliação do conceito de aprendizagem: novas formas de governar os sujeitos na atualidade}

Muitos autores têm corroborado com a discussão sobre a redefinição contemporânea dos conhecimentos escolares. Thomas Popkewitz (2001) fala em uma "alquimia das matérias escolares", salientando que os saberes disciplinares passam por uma espécie de alquimia e são reexaminados a partir das práticas de condução das condutas. Nas palavras do autor, "a instrução envolve questões relativas às disposições, às atitudes e aos sentimentos das crianças. [...] A ênfase está no desenvolvimento de comportamentos sociais e atitudes psicológicas" (POPKEWITZ, 2001, p. 79). Poderíamos pensar que ainda que se ensine o Português, a Matemática, as Ciências Biológicas, a História, a Geografia, parece-me que esses conhecimentos formais se articulam, ligam-se ou incluem outras dimensões tais como a organização das emoções e dos conflitos, as formas de se comportar e de se relacionar consigo e com os outros. Todas essas dimensões passam a ser tão importantes no currículo escolar que parecem 
entrar num jogo de concorrência com os conhecimentos formais ou escolares a ponto de redefini-los sob o prisma psicológico. Um não exclui o outro, mas o impregna, assumindo importância na escola, a ponto de pautarem o desenvolvimento de projetos e práticas específicas dentro das escolas. Ou seja, essa excessiva ênfase atribuída ao indivíduo na contemporaneidade e as práticas de governo de si mesmo não aparecem presentes apenas pelos encaminhamentos a especialistas diversos, mas encontram-se em projetos e práticas desenvolvidos pela própria escola. Isso pode ser evidenciado nos relatos dos diretores, quando descrevem práticas desenvolvidas pela escola que incluem seções de conversa em que se pode falar de si, elaborar conflitos e organizar emoções.

Há um projeto em que os adolescentes da escola (6. ${ }^{o s}$ e $7 .^{o s}$ Anos) são convidados a participar da Hora da Roda, atividades no turno de aula (1 encontro semanal) com coordenação da orientadora da escola $e$ estagiária em Psicologia. As atividades ocorrem de acordo com o interesse do grupo de alunos, buscando dar "voz" aos adolescentes, seus interesses, falar de si e se centrando no ponto de vista dos adolescentes da escola (Diretor A, 15 de abril de 2013).

Tem o programa municipal lançado por esta administração desde 2010, que se chama "Pacto pela Aprendizagem". Os alunos que reprovam estão automaticamente inseridos no programa que consiste em realizar encaminhamentos médicos que a escola deve fazer: neurologista, psicólogo, fonoaudiólogo... A escola faz o encaminhamento destes alunos, chama os pais e faz o encaminhamento para a rede de saúde, conforme a necessidade (neurologista, fono, psicólogo). É enviada uma lista com o nome destes alunos para a Smed para a pessoa que coordena o pacto. $\mathrm{Na}$ Smed, tem uma pessoa responsável pelo programa que monitora os encaminhamentos feitos pela escola e ela faz a ponte com a secretaria da saúde para estes alunos terem prioridade no atendimento. Cabe à escola também verificar se os pais estão levando os alunos aos atendimentos (Diretora C, Município 1, 21 de abril de 2013).

Os projetos desenvolvidos pelas escolas na Contemporaneidade enfatizam a condução das condutas dos sujeitos, com privilégio às práticas de si que incluem dimensões psicológicas. Popkewitz (2001, p. 80) destaca que "as técnicas de reflexão transformam os hábitos, as atitudes e as disposições da criança em disciplina escolar", ou seja, passam a ser considerados elementos do próprio conhecimento escolar. Isso inclui também outras áreas que aparecem 
nas narrativas por meio de uma variedade de especialistas. Vale destacar que, mesmo quando a diretora fala em uma ação municipal que foi nomeada "Pacto pela Aprendizagem", não visualizamos ali intervenções pedagógicas realizadas pela escola ou organizadas pela Secretaria de Educação, mas uma variedade de encaminhamentos para especialistas das mais diversas áreas: neurologistas, psiquiatras, fonoaudiólogos, psicólogos e outros. Esse fato mostra o quanto as questões trabalhadas por esses especialistas, seja o tratamento das emoções, a regulação dos comportamentos, sejam as intervenções $p s i$, medicamentosas ou, ainda, as mais variadas formas que fazem os sujeitos se tornarem capazes de conduzir a si mesmos, passam a ser consideradas aprendizagens escolares. Justo por isso é que podemos falar em uma sociedade da aprendizagem e que essa sociedade não está numa posição paradoxal àquilo que acontece no interior das escolas contemporâneas. A aprendizagem só ocupa a centralidade que é atribuída a ela nos dias de hoje porque ela não se relaciona mais, apenas, aos conhecimentos escolares como eram tradicionalmente definidos, mas a formas de vida, ou seja, ela incorpora as maneiras pelas quais cada sujeito se torna capaz de governar a si mesmo. Esse governo de si só pode acontecer mediante a construção de determinadas aprendizagens. Essa é a forma de governamento contemporâneo: um governamento pela aprendizagem.

Fundamentados nesse entendimento, autores como Simons e Masschelein (2008, p. 192) vêm trabalhando com a ideia de uma governamentalização da aprendizagem. Esses estudiosos esclarecem que a "[...] governamentalização da aprendizagem aponta precisamente para o que está em jogo hoje e que nós gostaríamos de descrever aqui: que a aprendizagem se converteu em um assunto tanto de governo como de autogoverno". A partir disso, podemos pensar que há uma governamentalização da aprendizagem no momento em que o sujeito torna-se capaz de governar a si mesmo a partir das aprendizagens que ele construiu e que incluem dimensões relacionais da vida humana. Por conclusão, é possível perceber a centralidade que a aprendizagem assume contemporaneamente como instrumento para a efetivação do governo de si, ou das práticas de condução centradas no si mesmo.

\section{REFERÊNCIAS}

CALIMAN, Luciana Vieira. A Biologia Moral da Atenção: a constituição do sujeito (des) atento. Rio de Janeiro: UERJ, 2006. Tese (Doutorado em Saúde Coletiva) - Instituto de Medicina Social, Universidade do Estado do Rio de Janeiro, Rio de Janeiro, 2006. 
COMENIUS, J. A. Didática Magna. São Paulo: Martins Fontes, 2002.

FOUCAULT, Michel. A Ordem do Discurso: aula inaugural no Collège de France, pronunciada em 2 de dezembro de 1970. 11. ed. Campinas: Loyola, 2004.

FOUCAULT, Michel. Ditos e escritos III-Estética: literatura e pintura, música e cinema. Rio de Janeiro: Forense Universitária, 2001a.

FOUCAULT, Michel. Os anormais: curso no Collège de France (1974-1975). São Paulo: Martins Fontes, 2001b.

KANT, Immanuel. Sobre a Pedagogia. São Paulo: UNIMEP, 1996.

MARÍN-DIAZ, Dora; NOGUERA-RAMÍREZ, Carlos Ernesto. Educar es governar. In: SALCEDO, Ruth Amanda Cortés; MARÍN-DIAZ, Dora Lilia. Gubernamentalidad y educación: discosiones contemporâneas. Bogotá, Colombia: IDEP, 2009. p. 127-151.

MISKOLCI, Richard. Estética da existência e pânico moral. In: RAGO, Margareth; VEIGA-NETO, Alfredo. Figuras de Foucault. Belo Horizonte: Autêntica, 2006. p. 227-238.

NÓVOA. Antônio. Professores: imagens do futuro presente. Lisboa: Educa, 2009.

Ó, Jorge Ramos do. O governo de si mesmo: modernidade pedagógica e encenações disciplinares do aluno liceal (último quartel do século XIX - Meados do século XX). Lisboa: Educa, 2003.

POPKEWITZ, Thomas. Lutando em defesa da alma: a política do ensino e a construção do professor. Porto Alegre: Artmed, 2001.

SIMONS, Maarten; MASSCHELEIN, Jan. Se nos hace crer que se trata de nuestra libertad: notas sobre la ironia del dispositivo de aprendizaje. Tradução de Carlos Ernesto Noguera-Ramírez. In: SMEYERS, Paul; DEPAEPE, Marc (Eds.). Educational Research (3): the educationalization of social problems. Springer, 2008, p. 191-204.

VEIGA-NETO, Alfredo. Crise da Modernidade e inovações curriculares: da disciplina para o controle. Revista Sísifo: Revista de Ciências da Educação. Faculdade de Psicologia e de Ciências da Educação da Universidade de Lisboa, n. 7, set./dez. 2008.

Texto recebido em 09 de dezembro de 2013. Texto aprovado em 08 de dezembro de 2014. 